\title{
QTcF Shortened
}

National Cancer Institute

\section{Source}

National Cancer Institute. QTCF Shortened. NCI Thesaurus. Code C112403.

An electrocardiog raphic finding in which the QT interval corrected for heart rate using Fridericia's formula is shortened. Thresholds for different age, gender, and patient populations exist. (CDISC) 